\title{
Structure and pigment make the eyed elater's eyespots black
}

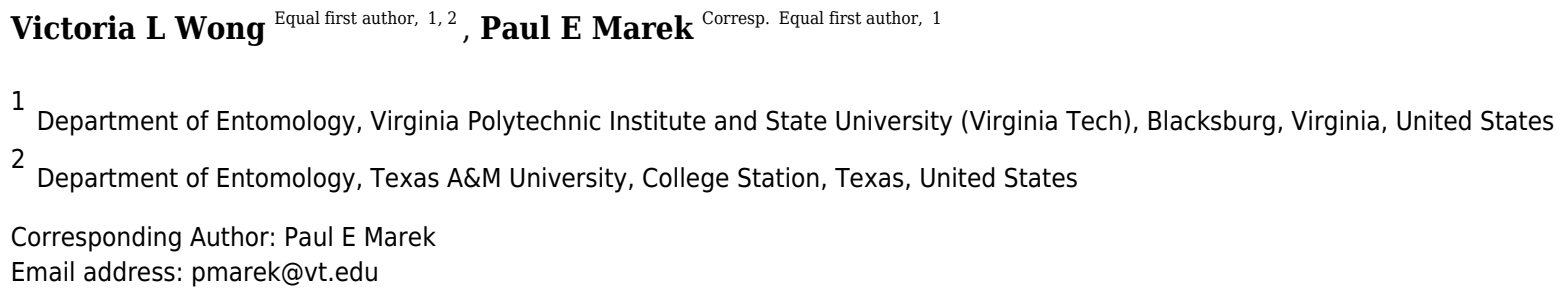

Surface structures that trap light leading to near complete structural absorption creates an appearance of "super black." Well known in the natural world from bird feathers and butterfly scales, super black has evolved independently from various anatomical structures. Due to an exceptional ability to reduce specular reflection, these biological materials have garnered interest from optical industries. Here we describe the false eyes of the eyed elater click beetle, which attains near complete absorption of light by an array of vertically-aligned microtubules. These cone-shaped microtubules are modified hairs (setae) that are localized to eyespots on the dorsum of the beetle, and absorb $96.1 \%$ of incident light (at a $24.8^{\circ}$ collection angle) in the spectrum between $300-700 \mathrm{~nm}$. Filled with melanin, the setae combine structure and pigment to generate multiple reflections and refractions causing light to travel a greater distance. This light-capturing architecture leaves little light available to receivers and the false eyes appear as deep black making them appear more conspicuous to predators. 


\section{Structure and pigment make the eyed elater's eyespots black}

2

3 Victoria Louise Wong ${ }^{1}$, Paul Edward Marek ${ }^{1}$

4

$5 \quad{ }^{1}$ Department of Entomology, Virginia Polytechnic Institute and State University (Virginia Tech),

6 Blacksburg, Virginia, United States

7

8

9 Corresponding author:

10

11 Paul Marek $^{1}$

12

13

14 Email address: paulemarek@gmail.com 
16

17

18

19

20

21

22

23

24

25

26

27

28

29

30

31

32

33

34

35

36

37

38

39

40

41

42

43

44

45

46

47

48

49

50

51

52

53

54

55

56

57

58

59

60

61

\section{Abstract}

Surface structures that trap light leading to near complete structural absorption creates an appearance of "super black." Well known in the natural world from bird feathers and butterfly scales, super black has evolved independently from various anatomical structures. Due to an exceptional ability to reduce specular reflection, these biological materials have garnered interest from optical industries. Here we describe the false eyes of the eyed elater click beetle, which attains near complete absorption of light by an array of vertically-aligned microtubules. These cone-shaped microtubules are modified hairs (setae) that are localized to eyespots on the dorsum of the beetle, and absorb $96.1 \%$ of incident light (at a $24.8^{\circ}$ collection angle) in the spectrum between $300-700 \mathrm{~nm}$. Filled with melanin, the setae combine structure and pigment to generate multiple reflections and refractions causing light to travel a greater distance. This light-capturing architecture leaves little light available to receivers and the false eyes appear as deep black making them appear more conspicuous to predators.

\section{Introduction}

Black in nature is often achieved by pigments (e.g. melanin) that absorb most visible light [1, 2]. In some cases, only ultraviolet light $(320-400 \mathrm{~nm})$ is reflected, such as in Asian whistlingthrushes [3]. Often, black pigment is overlaid by a glossy surface thereby imparting specular reflection increasing at angles normal to the illumination source, for example in many beetles [4]. Among insects, black pigmentation is typically achieved during the process of molting and tanning including sclerotization and melanization. In contrast, super black in butterflies, birds, and snakes is usually achieved by structural absorption [5] of nearly all ( $\geq 99 \%)$ light. Threedimensional structures, such as forest-like arrays of microtubules or polydisperse honeycomblike meshes on butterfly wings and the highly ramified barbules on bird of paradise feathers, act as a baffle to light $[6-8]$. (But, there are instances of "pseudo"-black achieved through additive mixing of structural green and magenta iridescence [4]). In some of these instances, super black structures evolved to impart varying degrees of reflection (blackness) dependent upon angle [7]. In others, structural absorption is assisted by melanin, and in jumping spiders, brush-like 3D scales absorb light and stray light is recaptured by an underlying melanin-containing layer [9]. Functional explanations of the evolutionary origins of super black include sexual selection [8], predator defense [10], and hydrophobicity [11]. In most of these examples of structural black, there is an array of protuberances on the surface of the animal that are perpendicularly oriented. These forest-like arrays of protuberances, which vary in composition from setae, microtrichia, barbules, and scales, have evolved repeatedly across the Tree of Life. Super black surface structures from nature have been applied to human industry since they have application for solar technology, a coating for the internal barrels of lenses in optical manufacturing, and artistic expression $[\mathbf{9}, \mathbf{1 2}, 13]$.

Known colloquially as the eyed elater or Eastern eyed click beetle, Alaus oculatus (Linneaus, 1758) (Fig. 1A, B) is a common beetle in the eastern U.S. with large and conspicuous eye-like spots on its back [14]. False eyes have evolved independently in several lineages of insects including moths, cockroaches and mantises, butterflies, and beetles [15]. Two lineages of click beetles (family Elateridae) in the subfamily Agrypninae possess ostensibly false eyes, including 
62 some members of the genus Alaus and individuals of the tribe Pyrophorini [16]. The latter

63 possess bioluminescent eyespots atop the pronotum and include the headlight elater (Pyrophorus

64 noctilucus), known colloquoially as the "cucuyo", and other pyrophorine genera from the

65 southern U.S. (e.g. Deilelater, Ignelater, Vesperelater). The bioluminescence of P. noctilucus is

66 so bright it can be seen from afar and, according to ship logs, was confused by Spanish

67 conquistadors with the smoldering matches of arquebusas held by indigenous inhabitants,

68 thereby discouraging attack [17]. Eyespots are often used to deter predators and function to

69 deflect attack to a non-vital body region or to startle predators [18]. These functions are the false-

70 head ("lose-little-to-save-much" ref. 19) and deimatic strategies [20]; however, in the case of the deimatic function it remains uncertain whether the eyespots deter attack because they appear as eyes (often of a larger, more intimidating animal) or due to their conspicuousness [18]. The false-head hypothesis for click beetles with eyespots atop their pronotum seems unlikely since the thorax houses vital organs such as the dorsal vessel and thoracic ganglia. Noting the similarity between the eyespots of the cucuyo and the eyed elater, McDermott [14] examined the latter to determine if the eyespots were "luminous, or at least have beneath its chitin some structure indicating that the eyespots were a degradation of the photogenic organs of the cucuyo". Although he found thicker cuticle underlying the eyespots, potentially due to muscular attachments of the thoracic cavity, no structures consistent with the photogenic organs of the cucuyo were found. McDermott [14] remarked that the false eyes may be "an extraordinary development of protective colouration."

As part of a study of structural coloration of insects in the Virginia Tech Insect Collection, we found striking examples of iridescence, but while observing the eyespots of A. oculatus in the collection and in the field in the Appalachian Mountains, we were struck by their profoundly black appearance at all angles. By depositing a thin metal film on the eyespots to prohibit absorption by pigments, we tested if structural absorption provides the black appearance. We compared the microstructures inside the periphery of the eyespots versus elsewhere on the exoskeleton of the beetle, and with the surface structural morphology of instances of super black in nature.

\section{Materials and methods}

We used material preserved in the Virginia Tech Insect Collection for this study (VTEC, collection.ento.vt.edu). Three adult specimens of $A$. oculatus were selected for the analysis. The individuals were pinned dried specimens collected from Virginia, Delaware, and Texas (U.S.A.) with the following VTEC catalog numbers: VTEC000000784, 5065, 5068, and 5069. To visually examine gross morphology, the eyespot of each specimen (right side) was examined at $45^{\circ}$ and $90^{\circ}$ angles with a Leica M125 stereomicroscope illuminated by a LED fiber optic light source. Setae composing the eyespot and the white ring encircling the eyespot (the "eyeliner") were removed with a straight-edge razor and mounted in glycerin on a microscope slide. Photographs of the setae were made with a Zeiss Axio Imager A2 microscope and AxioCam ERc5s camera, and a Leica DM500 microscope. The beetle specimen was photographed with a Canon EOS 6D digital SLR camera illuminated with two Canon Speedlite 430EXII flashes diffused with a paper cylinder. 
108 To test the hypothesis that structural absorption contributes to the deep black appearance,

109 eyespots were plasma coated with a thin layer of platinum $(\mathrm{Pt})$ and palladium $(\mathrm{Pd})$ metals to

110 control for absorption by pigments. From the middle of the right eyespot, including a piece of the

111 eyeliner and surrounding cuticle, a $4.25 \times 2.3 \mathrm{~mm}^{2}$ tile was removed with a straight-edge razor

112 and affixed on a $12.7 \mathrm{~mm}$ diameter aluminum scanning electron microscope (SEM) stub with

113 double-sided carbon tape. The stub was plasma coated under stable argon pressure with $20 \mathrm{~nm}$ of

114 Pt-Pd metals with a Leica EM ACE 600 high vacuum coater, and imaged on a FEI Quanta 600

115 FEG environmental SEM (5 kV, 3.5 spot size). A second round of 80-nm coating was carried out

116 to ensure that pigmentation was entirely concealed. Elemental analysis with energy dispersive X-

117 ray spectrometry (EDS) was then used to confirm that the SEM stub was evenly coated with

118 metals (Bruker AXS microanalysis system with XFlash SDD and e-Flash EBSD detectors). The

119 elemental composition of two sample areas - the stub surface and the eyespot setae - were

120 compared with EDS to test if the shape of two ED spectra were different (not superimposable)

121 and therefore indicative of a Pt-Pd coating deficiency. The width, spacing, direction and density

122 of setae on the eyespots were calculated from the SEM images using the program ImageJ version

$123 \quad 1.52 \mathrm{k}$ [21].

124

125

126

127

128

129

130

131

132

133

134

135

136

137

138

139

140

141

142

143

To measure reflectance, we used a spectrometer attached to a light source by a $400-\mu \mathrm{m}$ diameter fiber core reflectance probe with a $24.8^{\circ}$ acceptance angle (Ocean Optics USB 4000 spectrometer, QR400-7-UV fiber, and DH-BAL 2000 deuterium-halogen light source). A disc of polytetrafluoroethylene was used as a reflectance standard to calibrate the measurements (Ocean Optics WS-1). Reflectance measurements were made in a dark room with the probe oriented at a $45^{\circ}$ and normal incidence and at a detection distance of $3 \mathrm{~mm}$. Units are in percent reflectance, and are reflection factors, or empirical measurements of intensity normalized by the intensity of the reflectance standard. Reflectance was measured between $300-700 \mathrm{~nm}$, which encompasses the visible range of most animals. The eyespot, eyeliner, and the exoskeleton were measured from two individuals (VTEC000005068, 5069) three times. To compare the eyespot of the eyed elater against known instances of super black, the following butterfly specimens from the VTEC were measured using the same procedure: Ulysses swallowtail (Papilio ulysses, catalog number VTEC000000357) [6], Rajah Brooke's birdwing (Trogonoptera brookiana, VTEC000005067) [7], and the common rose (Pachliopta aristolochiae, VTEC000005066) [22]. Then, to quantify the contribution of light absorption that is structural, the reflectance of the eyespot and eyeliner were measured after metal-coating to prohibit pigmentary absorption. The $\mathrm{R}$ package pavo was used to analyze and visualize the reflectance measurements [23]. To calculate overall percent reflectance between $300-700 \mathrm{~nm}$, area beneath the curve of the spectrum was summed with Riemann sums and divided by the total area of $100 \%$ reflectance between $300-700 \mathrm{~nm}$.

144 Reflectance spectra were averaged, standard error of the mean calculated, and plotted using the $\mathrm{R}$ 145 package pavo.

146

147

148

149

150

151

152

153

\section{Results}

Based on visual examination with the light microscope, $A$. oculatus is generally black with white irregularly-shaped spots speckled across the body. The beetle possesses two large velvety black spots on the pronotum that are fringed in white eyeliner (Fig. 1C-D). The beetle is generally clothed with V-shaped seta of varying hue and texture, and the irregularly-shaped spots, white

Peerj reviewing PDF | (2019:06:38415:1:1:NEW 7 Oct 2019) 
154 eyeliner, and eyespots are made up of this seta. Outside of the eyespots, and generally distributed 155 across the cuticle of the beetle, the setae are brick red and have a smooth surface. The cuticle 156 outside of the eyespots is smooth and glossy with lustrous specular reflection. The setae of the 157 white eyeliner are rounded apically, translucent, and lack pigment (Fig. 2A, B). Eyeliner setae 158 and those outside of the eyespots are decumbent (Fig. $2 \mathrm{~F}-\mathrm{H}$ ). In contrast the setae inside the periphery of the eyespots are erect, acuminate apically, black with longitudinal grooves, and evenly spaced (Figs 2A, C - H, K, 3A). The V-shaped setae in the eyespots are more canoeshaped than the others, with a flat slightly concave face opposite of the convex (hull) side (Fig. 2A, C, D, K). With the grooves, these setae appear as caraway seeds cut in half longitudinally, striped with lines running along its length (Fig. 2A, C-G, K). By fracturing its cuticular layer, the eyespot and eyeliner setae contain numerous densely-packed melanosome-like spherules (Fig. 2I, J, L, M). The cuticle underlying the eyespots is glossy and similar to the cuticle outside of the eyespots; however, its surface is recessed and dimpled around setal sockets (Fig. 3B - D).

When viewed at a $90^{\circ}$ angle, even with the bright illumination of the microscope (illuminated at ca. $45^{\circ}$ ), little surface structure was apparent and the eyespots appeared profoundly black, appearing as voids in the body (Fig. 1C). When viewed at a $45^{\circ}$ angle (and more acute angles), surface structure was discernable and the setae appeared regularly spaced with the concave side (hull) of the canoe-shaped hairs consistently facing outwards in a ring encircling the periphery of the eyespot (Fig. 3A, Supplementary figure 4). The other half of the setae are in the center of the eyespot and appear to be facing random directions (Supplementary figure 4). Along the periphery, the setae of the eyespots are bent at a ca. $60^{\circ}$ angle and gradually change in angle to $90^{\circ}$ at the center of the eyespot; in contrast, the setae at the posterior-facing margin remain upright and ca. $90^{\circ}$ (Fig. 3A, Supplementary figure 1).

The EDS analysis of the sample areas resulted in ED spectra with the same shape (superimposable spectral profiles) and identical elemental composition with uniform coating (Supplementary figures 2, 3). Micrographs of the eyespot setae at $2.5 \times 10^{4}$ magnification were recorded without building of charges indicating a fully conductive surface and a complete Pt-Pd coating (Supplementary figure 4). As a result of plasma coating, the SEM stub and non-eyespot portions of the cuticle sample possessed a lustrous metallic surface. When viewed from the side at a shallow angle $\left(15-30^{\circ}\right.$ from the surface of the stub), the eyespot setae have a specular metallic sheen, indicating thorough coating. However, despite uniform metal coating, the eyespot retained a deep black appearance at normal incidence (Fig. 4, Supplementary Movie). Based on examination of the eyespots with the SEM (between 326 - 5,033X magnification), the V-shaped seta are lined with about 14 longitudinal ridges $($ mean $=13.97$, standard deviation $=1.92, \mathrm{n}=30$ ) with a smooth somewhat concave opposing surface (Fig. 2A, D, E). The ridges that line the setae longitudinally are each $4.28 \mu \mathrm{m}$ wide (mean, standard deviation $=0.45 \mu \mathrm{m}, \mathrm{n}=30$ ). The pointed apices of the setae are dividing into two or occasionally three shallow furcations (Fig. 2E). Setae are about $38.33 \mu \mathrm{m}$ in widest width (mean, standard deviation $=2.15, \mathrm{n}=30$ ) and spaced about $10.30 \mu \mathrm{m}$ edge-to-edge from one another (mean, standard deviation $=2.67, \mathrm{n}=30$ ). Within in a $726.68 \mu \mathrm{m}^{2}$ area of the eyespot there are 250 setae, and 1,756 setae within the eyespot area in total.

From the measurement of reflectance, the white eyeliner, the glossy exoskeleton and the black eyespot possessed spectra of different shapes (Fig. 5). The black eyespot spectrum was a flat 
200 profile, indicating a general lack of reflectance across a broad range of wavelengths. The white

201

202

203

204

205

206

207

208

209

210

211

212

213

214

215

216

217

218

219

220

221

222

223

224

225

226

227

228

229

230

231

232

233

234

235

236

237

238

239

240

241

242

243

244

245

eyeliner spectrum had a plateau shape, lacked near-ultraviolet reflectance, and with uniformly high reflectance between $400-700 \mathrm{~nm}$. The glossy exoskeleton spectrum was generally flat in profile but with consistently high overall reflectance (including ultraviolet) indicating a high glare from the lustrous cuticular surface. The overall reflectance of the black eyespot patch was $3.90 \%$, the white eyeliner was $32.92 \%$, and glossy exoskeleton was $46.14 \%$. The overall reflectance of the super black wing patches of the butterflies $T$. brookiana, $P$. ulysses, and $P$. aristolochiae were more than six-fold less than that of the beetle's eyespot: $0.51 \%, 0.55 \%$, and $0.71 \%$. The overall reflectance of the black eyespot measured at a $45^{\circ}$ specular orientation from three directions (posteriad, mesad, and anteriad) were ten-fold less than that at $90^{\circ}: 0.30 \%$, $0.36 \%$, and $0.38 \%$. To quantify the contribution of light absorption that is structural, the overall reflectance of the metal-coated structures were $10.38 \%$ for the eyespot (2.66-fold greater than the uncoated) and $44.56 \%$ for the eyeliner (11.42-fold greater than the uncoated).

\section{Discussion}

We found that structural absorption gives a black appearance to the eyespots of $A$. oculatus. By depositing a thin metal film on the eyespots to prohibit light absorption by pigments, we demonstrated that pigmentation alone is not responsible for their deep black color. Based on our examination of the black eyespots, we found that their surface morphology was equivalent in shape, orientation, and general photonic properties of super black structures in nature. In particular, the eyespot composed an array of perpendicularly aligned linear protuberances that absorb $96.1 \%$ of light and is analogous to the three-dimensional array of microtubules on butterfly wings [6] and the ramified barbules on bird of paradise feathers [8] and jumping spiders [9]. However, the perpendicularly aligned array of setae on the eyed elater's eyespot is scaled up ten-fold relative to the super black examples in other animals $(10 \mu \mathrm{m}$ between neighboring eyespot setae versus $1 \mu \mathrm{m}$ in spiders). Though the morphology is analogous, the magnitude of scale may account for the quantitative difference in absorption of light. Other examples of structural black in nature with similar perpendicularly aligned protuberances include the cuticular papillae of stick insects [11] and leaf-like microstructures on viper and peacock spider scales $[9,10]$. Functionally equivalent super black structures in butterflies include polydisperse honeycomb-like meshes of the wing scales of the Ulysses swallowtail [6], Rajah Brooke's birdwing [7], and the common rose [22]. Though a different morphology, these meshes are ostensibly negative casts of perpendicularly aligned microtubule arrays, and synthesized $\mathrm{SiO}_{2}$ negative replicas derived similar light-absorbing capabilities of their biological templates [7]. All of these surface structures generate multiple reflections and refractions causing light to travel a greater distance, causing structural absorption and leaving little light available to reach the viewer's eye. While human-fabricated super black materials typically absorb $99.965-99.995 \%$ of light $[\mathbf{2 4}, \mathbf{2 5}$, in nature, bird of paradise feathers come close to this with incident reflectance of about $0.05 \%$. Butterflies and spiders with super black patches reflect more (incident) light with between about $0.35 \%-0.71 \%$.

Melanin is a ubiquitous black pigment of insect exoskeletons, and is a component of the setae of the eyed elater's eyespots. Melanin contributes to the black color of the eyespots by absorbing light in concert with structural absorption. The pigment directly absorbs light and perhaps also

Peer] reviewing PDF | (2019:06:38415:1:1:NEW 7 Oct 2019) 
246

247

248

249

250

251

252

253

254

255

256

257

258

259

260

261

262

263

264

265

266

267

268

269

270

271

272

273

274

275

276

277

278

279

280

281

282

283

284

285

286

287

288

289

290

291

recaptures light that strays from structural absorption. We showed that the eyespot setae sit in a concavity (Fig. 3B - D), and the cuticle underlying the eyespots has a dimpled topography. These concavities are smooth and have a black pigmentation. Other arthropods possess similarly shaped concavities that scatter light and impart additive mixing (of blue and yellow iridescence such as in the emerald swallowtail [26]), or augment melanin absorption thereby increasing overall absorption and producing super black (as in peacock spiders [9]). These concavities of the eyed elater's eyespots and the fourteen $4.28-\mu \mathrm{m}$ wide longitudinal ribs on the setae could be features that assist to impart a black color. Additionally, scattering of light may be directional (e.g. backwards) given the shape and orientation of the setae on the eyespots. Optical modeling integrating these features would be fruitful to understand how this ensemble of features work in concert to affect light.

The function of super black eyespots in the eyed elater may be for predator deterrence including aposematism, deimatism, or as a false head. A role as a false head is unlikely since the eyespots are in close proximity to the real head and not posteriorly located as in other insects $(e . g$. hairstreak butterflies). Since there are large dorsal intersegmental muscles directly beneath the eyespots [27], thermoregulation or muscle-heating is another functional hypothesis. While the startle function is the most likely, click beetles do have a powerful clicking mechanism that is noxious to birds $[\mathbf{2 7}, \mathbf{2 8}]$ and disentangling this aposematic role versus a startle function would ideally be tested using field experiments.

The study of super black structures in nature have uncovered a diversity of morphologies that cause near complete absorption of light. A result of convergent evolution, analogous structures such as honeycomb-like meshes and perpendicularly-aligned arrays have originated to act as a general baffle of light for various functional roles. Since super black materials have application for human industry (e.g. solar cells, artistic expression, etc.) the structural morphology of these various materials in nature are an ideal domain as creativeness for fabricating structures and as a means to understand the evolution of adaptive coloration and natural selection.

\section{Conclusions}

In this study, we asked: what makes the eyespots of the eyed elater black? We found that the eyespots comprise an array of perpendicularly aligned setae with black pigmentation. The eyespot is circled by a ring of clear setae that lay flat and appear white, the "eyeliner". The black eyespot absorbs $96.1 \%$ of incident light, ten-fold more than the eyeliner. A collaboration between structural and pigmentary absorption, multiple reflections and refractions increase the distance that light travels thereby reducing the amount of light available to the receiver. The intense black of the eyespot provides a stark contrast versus the eyeliner making the eyespots conspicuous to a predator. Ostensibly an aposematic signal to warn of the beetle's noxious clicking behavior and increased handling time, the highly apparent eyespots may also serve a startle (deimatic) function making the beetle appear as a larger, more formidable opponent.

\section{Acknowledgements}


292 Thanks to Drs. Ellen Brown and Barry Lee Bressler for support of the Virginia Tech Insect

293 Collection and a donation of beetle specimens, including the two eyed elaters used in this study.

294 Jackson Means assisted with counting the ridges on setae. Doro Tholl provided access to the

295 Zeiss microscope. Steve McCartney and Chris Winkler at the Nanoscale Characterization and

296 Fabrication Laboratory at the Virginia Tech Institute for Critical Technology and Applied

297 Science assisted with SEM and EDS. We are grateful to Charity Hall for editing previous

298 versions of the manuscript, and anonymous reviewers for suggestions and improvements.

299

300

301

302

303

304

305

306

307

308

309

310

311

312

313

314

315

316

317

318

319

320

321

322

323

324

325

326

327

328

329

330

331

332

333

334

335

\section{References}

1. Zhang L, Arnaud A, Perry MW, van der Burg KRL, Matsuoka Y, Monteiro A, Reed RD 2017 Genetic basis of melanin pigmentation in butterfly wings. Genetics 205, 1537-1550. (doi.org/10.1534/genetics.116.196451)

2. Hsiung B, Blackledge, TA, Shawkey MD 2015 Spiders do have melanin after all. J. Exp. Biol. 218, 3632-3635. (doi.org/10.1242/jeb.128801)

3. Andersson S 1996 Bright ultraviolet colouration in the Asian whistling-thrushes (Myiophonus spp.). Proc. R. Soc. Lond. B 263, 843-848.

4. Seago AE, Brady P, Vigneron J, Schultz TD 2009 Gold bugs and beyond: a review of iridescence and structural colour mechanisms in beetles (Coleoptera) 6, S165-S184. (doi.org/10.1098/rsif.2008.0354.focus)

5. Vukusic P 2009 Advanced Photonic Systems on the Wing-Scales of Lepidoptera. In: Functional Surfaces in Biology. Ed. Gorb S. pp. 237 - 258. London: Springer.

6. Vukusic P, Sambles JR, Lawrence CR 2004 Structurally assisted blackness in butterfly scales 271, S237-S239. (doi.org/10.1098/rsb1.2003.0150)

7. Han Z, Li B, Mu Z, Yang M, Niu S, Zhang J, Ren L 2015. An ingenious super light trapping surface templated from butterfly wing scales. Nanoscale research letters, 10, 344. (doi.org/10.1186/s11671-015-1052-7)

8. McCoy DE, Feo T, Harvey TA, Prum RO 2018 Structural absorption by barbule microstructures of super black bird of paradise feathers. Nature Communications 9, 1-8. (doi.org/10.1038/s41467-017-02088-w) 
336

337

338

339

340

341

342

343

344

345

346

347

348

349

350

351

352

353

354

355

356

357

358

359

360

361

362

363

364

365

366

367

368

369

370

371

372

373

374

375

376

377

378

379

380
9. McCoy DE, McCoy VE, Mandsberg NK, Shneidman AV, Aizenberg J, Prum RO, Haig D 2019 Structurally assisted super black in colourful peacock spiders. Proc. R. Soc. B 286, 1-9. (doi.org/10.1098/rspb.2019.0589)

10. Spinner M, Kovalev A, Gorb SN, Westhoff G 2013 Snake velvet black: hierarchical micro- and nanostructure enhances dark colouration in Bitis rhinoceros. Scientific Reports 3, 1-8. (doi.org/10.1038/srep01846)

11. Maurer DL, Kohl T, Gebhardt MJ 2017 Cuticular microstructures turn specular black into matt black in a stick insect. Arthropod Structure \& Development 46, 147-155. (doi.org/10.1016/j.asd.2016.11.006)

12. Kennedy R 2016 In Boston, a Major Della Robbia Show, New York Times, August 3, 2016 https://www.nytimes.com/2016/08/07/arts/design/in-boston-a-major-della-robbiashow.html

13. Zhao Q, Tongxian F, Ding J, Zhang D, Guo Q, Kamada M 2011 Super black and ultrathin amorphous carbon film inspired by anti-reflection architecture in butterfly wings. Carbon 49, 877-883. (doi.org/10.1016/j.carbon.2010.10.048)

14. McDermott FA 1911 The "eye-spots" of Alaus oculatus. The Canadian Entomologist 43, 190-192. (doi.org/10.4039/Ent43190-6)

15. Misof B, Liu S, Meusemann K, Peters RS, Donath A, Mayer C, Frandsen PB, Ware J, Flouri T, Beutel RG and Niehuis O, 2014 Phylogenomics resolves the timing and pattern of insect evolution. Science 346, 763-767. (doi.org/10.1126/science.1257570)

16. Kundrata R, Bocakova M, Bocak L 2014 The comprehensive phylogeny of the superfamily Elateroidea (Coleoptera: Elateriformia). Mol. Phylogen. Evol. 76, 162-171.

17. Perkins GA 1868 The Cucuyo, or West Indian Fire Beetle. The American Naturalist 2, 422-433. (doi.org/10.1086/270276)

18. Skelhorn J, Holmes GG, Hossie TJ, Sherratt TN 2016 Eyespots. Current Biology 26, R52-R54. (doi.org/10.1016/j.cub.2015.10.024)

19. Sourakov, A 2013 Two heads are better than one: false head allows Calycopis cecrops (Lycaenidae) to escape predation by a Jumping Spider, Phidippus pulcherrimus (Salticidae). Journal of Natural History 47, 1047-1054.

(doi.org/10.1080/00222933.2012.759288)

20. Umbers DL, Lehtonen J, Mappes J 2015 Deimatic displays. Current Biology 25, R58R59. (doi.org/10.1016/j.cub.2014.11.011) 
21. Rasband, WS 2019 ImageJ, U. S. National Institutes of Health, Bethesda, Maryland, USA, https://imagej.nih.gov/ij/

22. Siddique, R. H., Donie, Y. J., Gomard, G., Yalamanchili, S., Merdzhanova, T., Lemmer, U., \& Hölscher, H. 2017 Bioinspired phase-separated disordered nanostructures for thin photovoltaic absorbers. Science Advances, 3, e1700232. (doi.org/10.1126/sciadv.1700232)

23. Maia R, Eliason CM, Bitton PP, Doucet SM, Shawkey MD 2013 pavo: an R package for the analysis, visualization and organization of spectral data. Methods in Ecology and Evolution 4, 906-913. (doi.org/10.1111/2041-210X.12069)

24. Cui K, Wardle, BL 2019 Breakdown of Native Oxide Enables Multifunctional, FreeForm Carbon Nanotube-Metal Hierarchical Architectures. ACS Applied Materials \& Interfaces 11, 35212-35220. (doi.org/10.1021/acsami.9b08290)

25. Theocharous E, Chunnilall CJ, Mole R, Gibbs D, Fox N, Shang N, Howlett G, Jensen B, Taylor R, Reveles JR, Harris OB 2014. The partial space qualification of a vertically aligned carbon nanotube coating on aluminium substrates for EO applications. Optics Express, 22, 7290-7307. (doi.org/10.1364/OE.22.007290)

26. Vukusic P, Sambles JR, Lawrence CR 2000 Colour mixing in wing scales of a butterfly. Nature 404, 457. (doi.org/10.1038/35006561)

27. Evans MEG 1973 The jump of the click beetle (Coleoptera: Elateridae) — energetics and mechanics. J. Zool., Lond. 169, 181-194. (doi.org/10.1111/j.1469-7998.1972.tb03115.x)

28. Eisner T, Eisner M, Siegler M 2005 Secret Weapons: Defenses of Insects, Spiders, Scorpions, and Other Many-Legged Creatures. p. 384. Harvard, MA: Harvard University Press.

29. Wong V, Marek PE 2019 Data from: Super black eyespots of the Eyed elater. [Dataset] VTechData repository for Virginia Tech (https://data.lib.vt.edu/collections/rf55z781b) 
Figure 1

Eyed elater click beetle, Alaus oculatus, dorsal habitus and false eyes

Figure 1 Eyed elater click beetle, Alaus oculatus, (A) dorsal habitus view, (B) right lateral view (scale bar $=2.0 \mathrm{~mm}$ ); eyed elater false eyes, (C) left dorsal view, (D) right oblique view (scale bar $=0.5 \mathrm{~mm}$ ). 

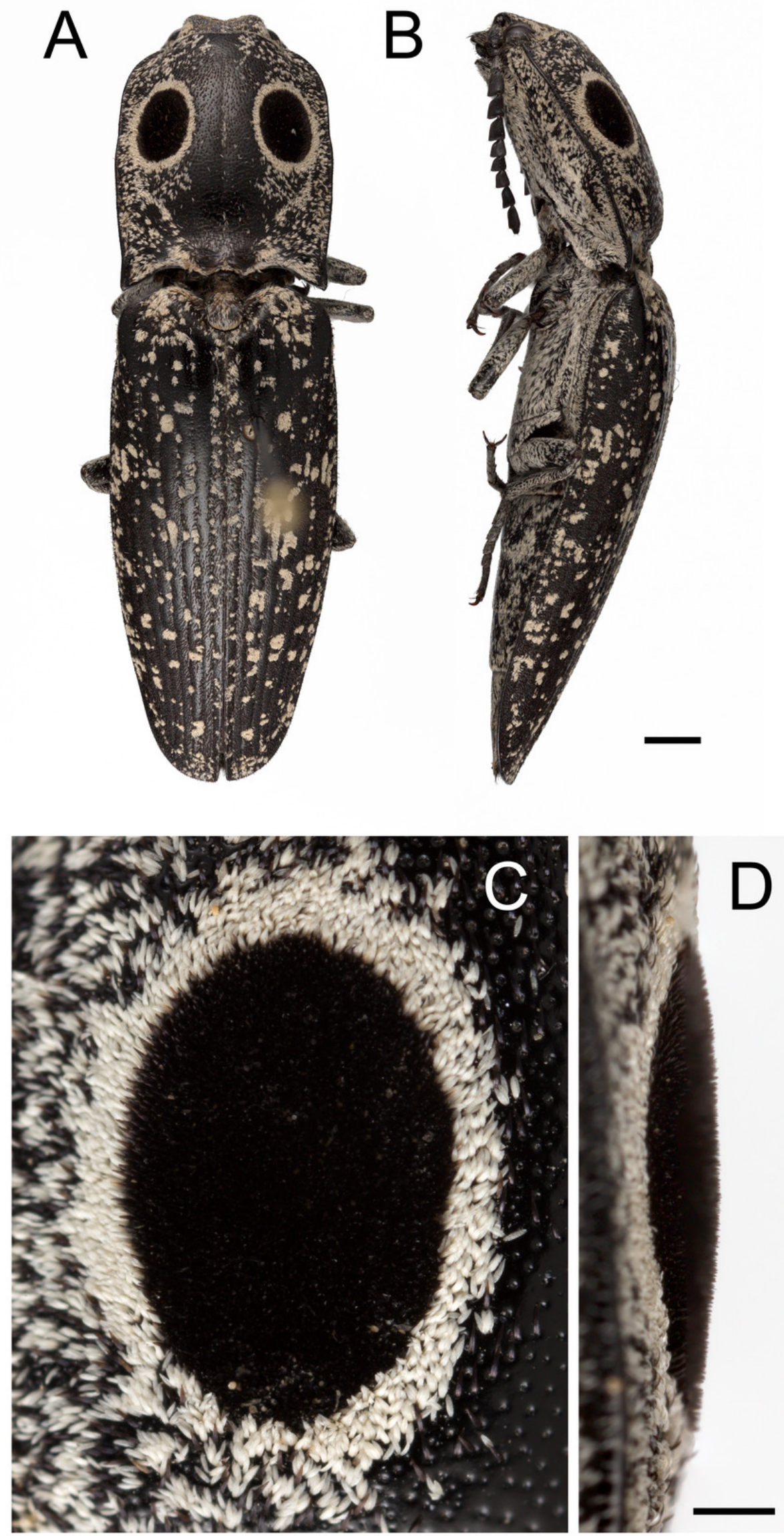


\section{Figure 2}

Eyed elater click beetle, Alaus oculatus, setal morphology of false eyes and eyeliner.

Figure 2 Eyed elater click beetle, Alaus oculatus, setal morphology, (A) transmitted light color photograph of eyespot (bottom) and eyeliner (top) setae (scale bar $=50.0 \mu \mathrm{m}$ ), (B) transmitted light photograph of eyeliner seta with bubble trapped behind showing transparency (scale bar $=30.0 \mu \mathrm{m}$ ), (C) scanning electron micrograph (SEM) of the eyespot setae, magnified 326X (scale bar $=0.2 \mathrm{~mm}$ ), (D) same, 1247X (scale bar $=0.05 \mathrm{~mm}$ ), (E) same, $5033 \mathrm{X}$ (scale bar $=0.01 \mathrm{~mm}$ ), (F) SEM of cephalic right corner of eyespot (scale bar = $250 \mu \mathrm{m}$ ), dashed rectangle (in G) showing perpendicular eyespot setae on left and decumbent eyeliner setae on right (scale bar $=100 \mu \mathrm{m}),(\mathrm{H})$ SEM of cephalic side of the eyespot (scale bar $=1 \mathrm{~mm}$ ), (I) SEM of interior of an eyespot seta with melanosome-like spherules packed inside (scale bar $=2 \mu \mathrm{m}$ ), (J) same, 100000X (scale bar $=200 \mathrm{~nm}$ ), (K) SEM of eyespot seta (scale bar $=60 \mu \mathrm{m}$ ), (L) SEM of interior of an eyeliner seta with melanosomelike spherules packed inside (scale bar $=2 \mu \mathrm{m}$ ), (M) same, 100000X (scale bar $=200 \mathrm{~nm}$ ) 


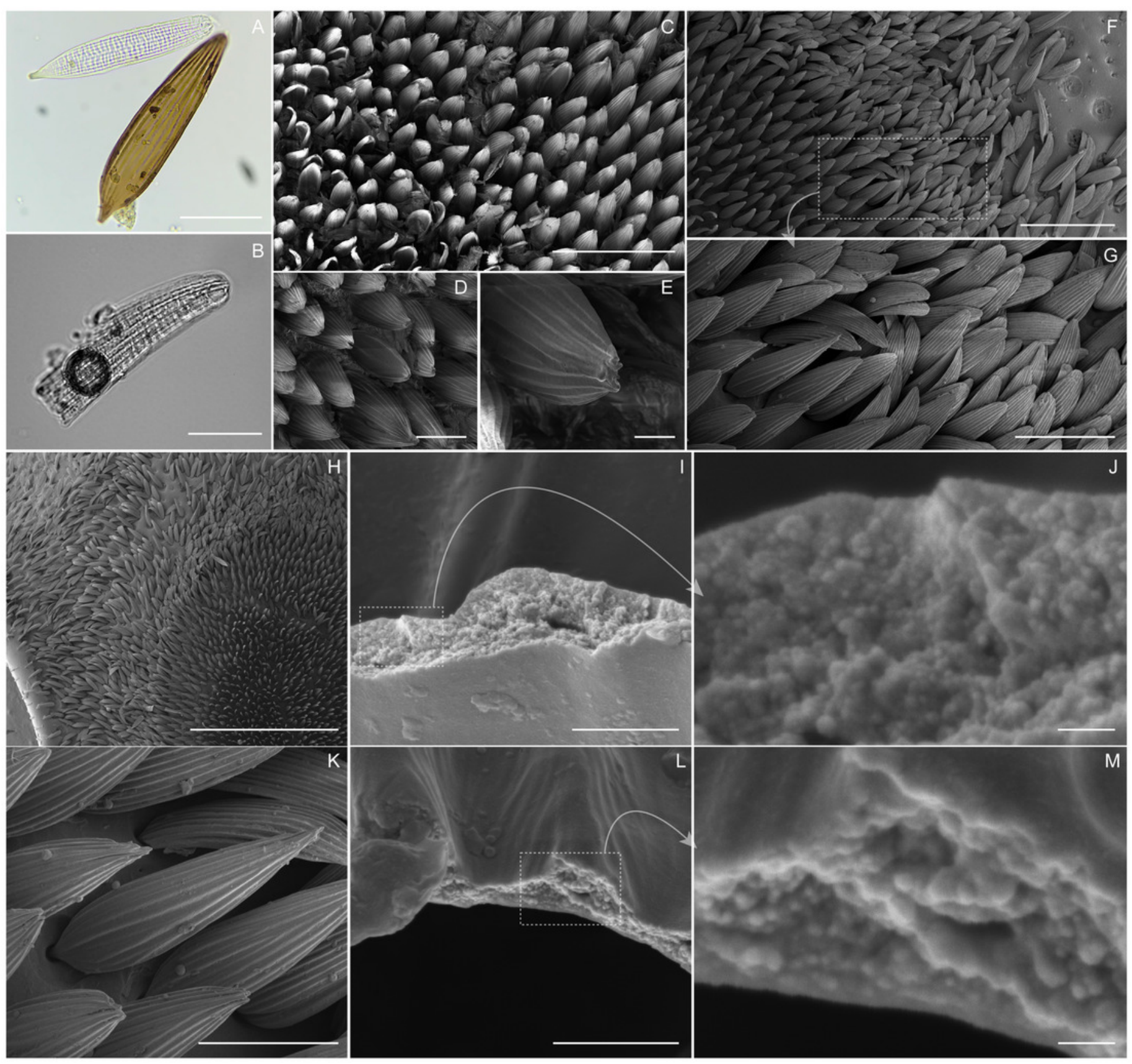




\section{Figure 3}

Eyed elater click beetle, Alaus oculatus, false eyes, lateral view and exoskeletal dimples of eyespot setae

Figure 3 Eyed elater click beetle, Alaus oculatus, false eyes, (A) lateral view (scale bar $=1.0$ $\mathrm{mm}$ ); (B) right dorsal view, dimples denoted by arrows, eyeliner setae in middle (scale bar = $0.5 \mathrm{~mm}$ ) [left side of $A$ and $B$ is cephalic]; (C) dorsal view with setae removed (scale bar $=1$ $\mathrm{mm}) ;(\mathrm{D})$ same, $728 \mathrm{X}$ (scale bar $=100 \mu \mathrm{m})$

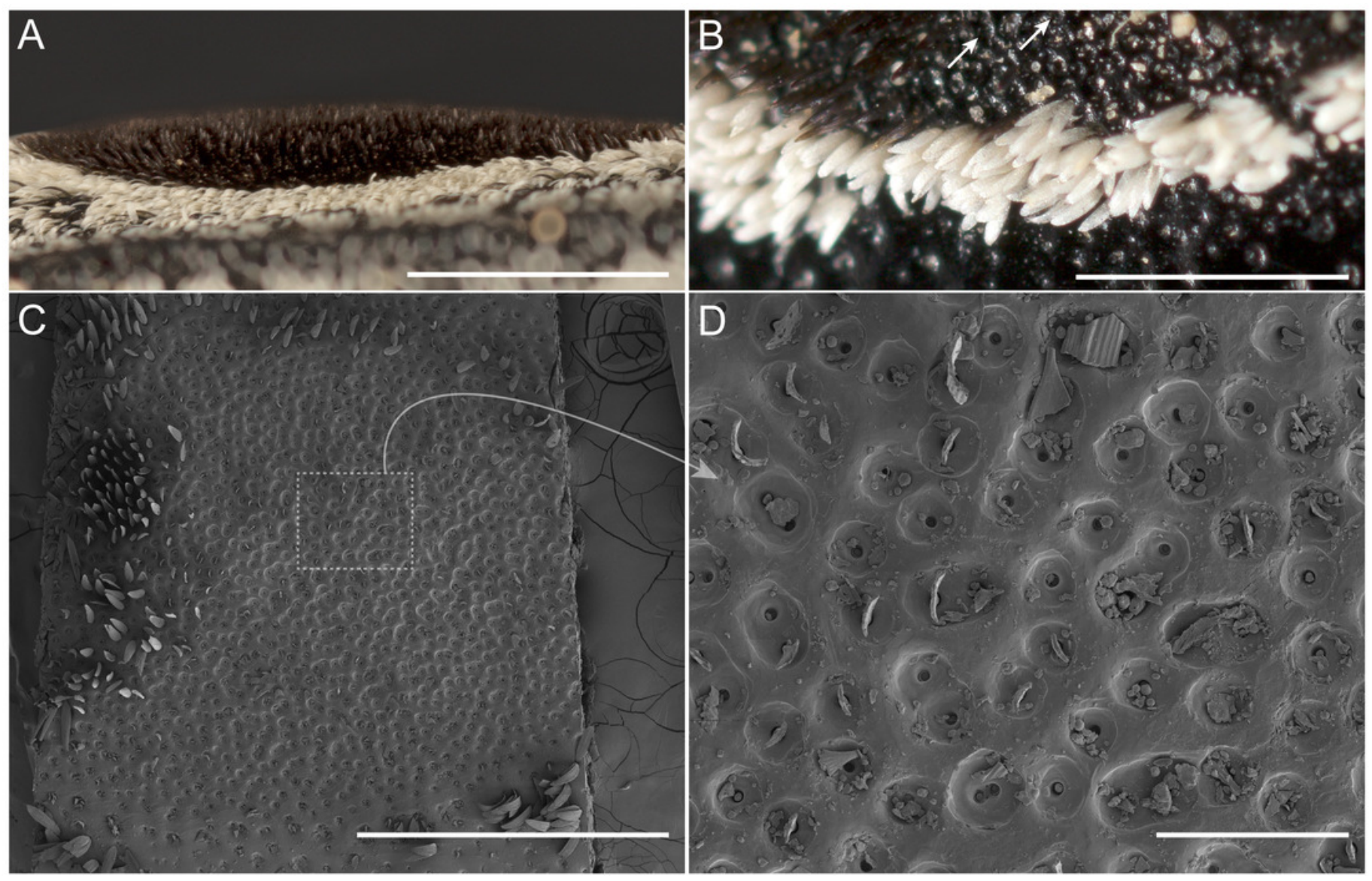


Figure 4

Eyed elater click beetle false eyespot and eyeliner coated with a 100-nm layer of platinum and palladium

Figure 4 Eyed elater click beetle, Alaus oculatus, eyespot (top white arrows) and eyeliner (bottom black arrows) coated with a 100-nm layer of platinum and palladium, (A) $15^{\circ}$ view, (B) $30^{\circ}$ view, (C) $45^{\circ}$ view, (D) $60^{\circ}$ view, (E) $75^{\circ}$ view, (F) $90^{\circ}$ view (scale bar $=1.0 \mathrm{~mm}$ ) 


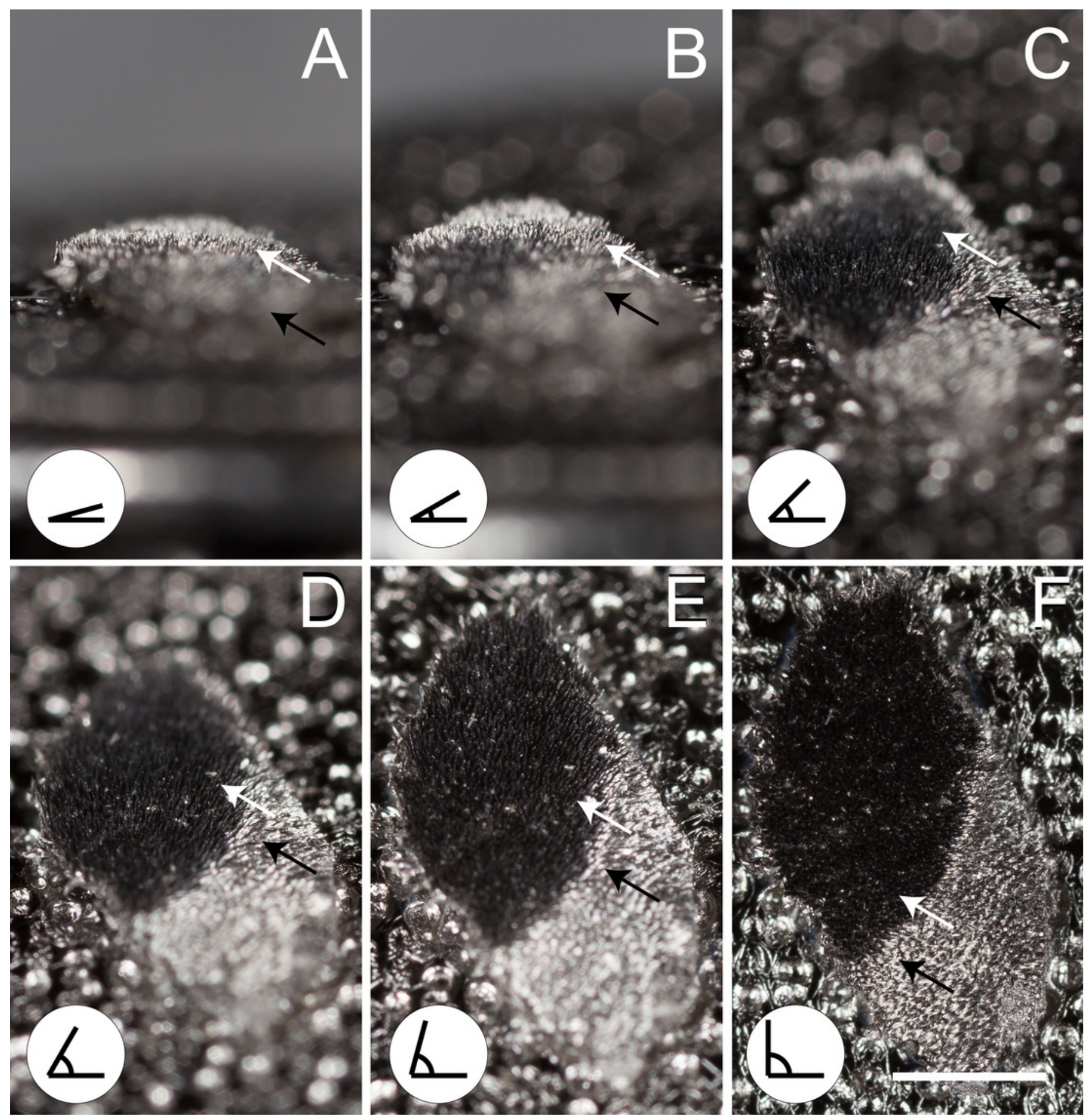




\section{Figure 5}

Reflectance spectra of the eyed elater eyespot and butterflies with super black wing scales (A) and schematic (B) of proposed structural light absorbing mechanism

Figure 5 Reflectance spectra of the eyed elater eyespot and butterflies with super black wing scales (A), and schematic (B) of proposed structural light absorbing mechanism (solid line $=$ light propagating through air; dashed line = light propagating through solid), blue spectrum line $=$ eyespot (ey), red = white eyeliner (el), green = glossy cuticle (cu), dashed brown $=$ Ulysses swallowtail (pictured), dashed purple $=$ Rajah Brooke's birdwing, dashed teal $=$ common rose
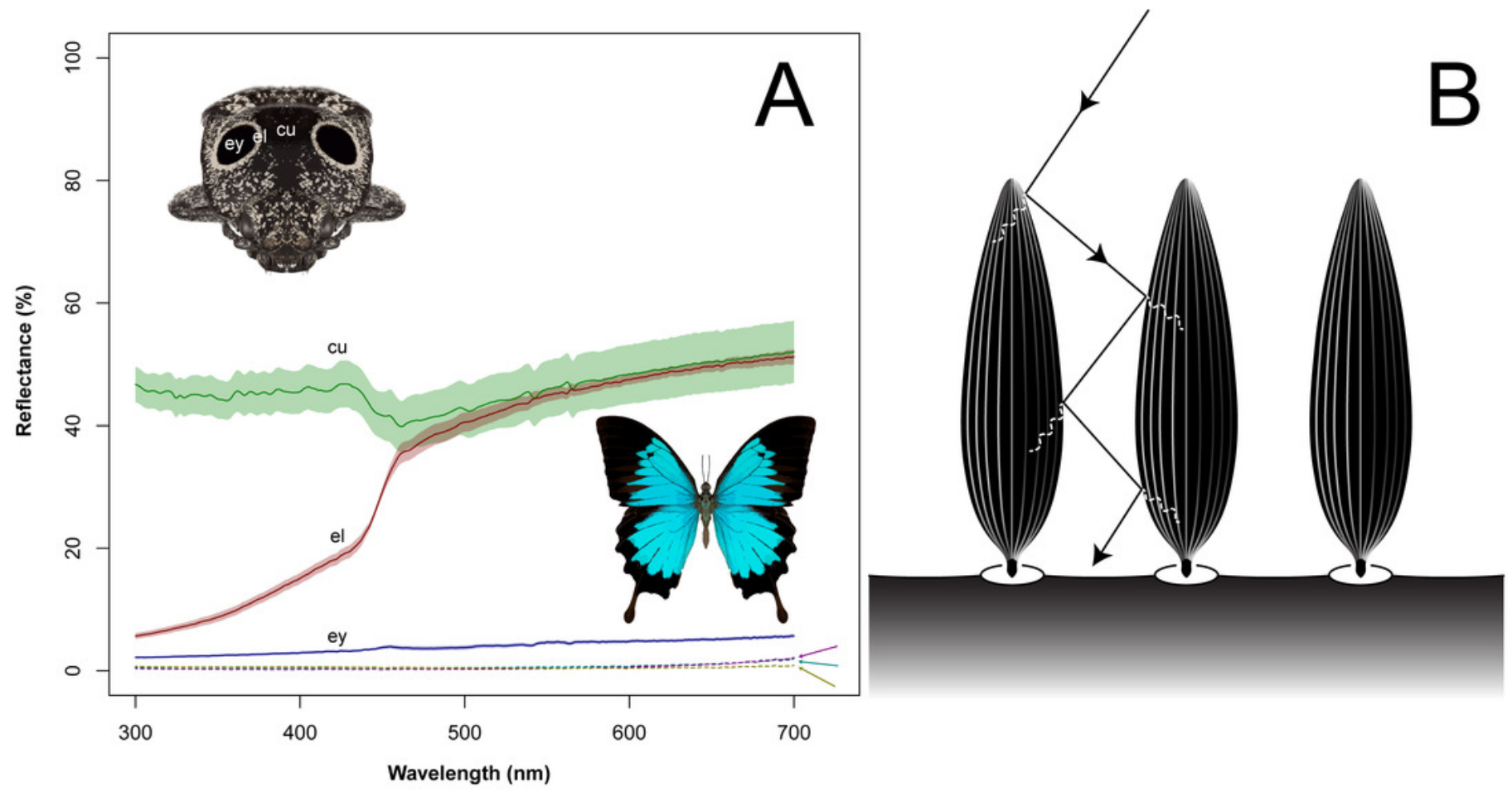